\title{
Household food insecurity and child health
}

\author{
Kammi K. Schmeer* and Barbara A. Piperata ${ }^{\dagger}$ \\ "Department of Sociology, The Ohio State University, Columbus, USA, and 'Department of Anthropology, The Ohio State University, Columbus, USA
}

\begin{abstract}
Food insecurity, the lack of consistent access to sufficient quality and quantity of food, affects an estimated 800 million people around the world. Although household food insecurity is generally associated with poor child nutrition and health in the USA, we know less about household food insecurity and child health in developing countries. Particularly lacking is research assessing how associations between household food insecurity and children's health outcomes may differ by child age and among children beyond age 5 years in low-income settings. We use data from a population-based sample of households with children ages 3-11 years $(N=431)$ in León, Nicaragua to consider how household food insecurity is associated with three measures of child health: illness, anaemia and low heightfor-age. Our results provide new evidence that even mild household food insecurity is detrimental to children's health; and that child age conditions the associations between household food insecurity and child health. We find that food insecurity is especially harmful to health during early childhood, but continues to have significant associations with health into middle childhood (up to ages 7-8 years). We discuss the potential implications of these results for future child health research and policies in low-income countries. (C) 2016 John Wiley \& Sons Ltd
\end{abstract}

Keywords: child nutrition, child public, health, food security, poverty, low income countries, international child health nutritionbreastfeeding.

Correspondence: Kammi K. Schmeer, Department of Sociology, The Ohio State University, Columbus, USA. E-mail: schmeer.1@osu.edu

\section{Introduction}

Despite national and international efforts to increase the global availability of food, as of 2013, an estimated 800 million people were food insecure, most of whom reside in low- and middle-income countries (FAO 2014). For children, the lack of consistent access to sufficient quality and quantity of food is particularly concerning, as household food insecurity may result in dietary deficiencies that limit their physical growth and cognitive development (Allen 2006). Psychosocial stressors induced by food insecurity (Hadley \& Crooks 2012, Hadley et al. 2012, Melchior et al. 2012) may further increase children's susceptibility to illness and growth faltering during critical periods of development. Childhood health, in turn, has implications for both educational attainment and later economic productivity (Currie \& Vogl 2013). Food insecurity is thus an important pathway in the intergenerational cycle of poverty and poor health.

A recent review of US research indicates a substantial body of work demonstrating the negative effects of household food insecurity on child health across a number of outcomes (Coleman-Jensen et al. 2013). Comparatively less research has been done in developing countries (KursmarkWeitzman 2009, Nord 2014); however, recent studies in low-income settings have found significant associations between household food insecurity and higher risk of illness (Anderson et al. 2012), anaemia (Campbell et al. 2011), stunting (Hackett et al. 2009; Cuevas-Nasu et al. 2014) and underweight status (Hackett et al. 2009) in infants and children under 5 years.

We seek to advance the current body of research on food insecurity and child health in developing country contexts by assessing how household food insecurity is associated with multiple health measures (e.g. illness, anaemia and low-height-for-age) in children ages 311 years in León, Nicaragua. Importantly, we consider the associations between household food insecurity and child health outcomes across a broader child age range than in most previous studies, and we assess whether these associations differ by child age. Although 
child health policy emphasizes the importance of the first 1000 days (conception through 2 years), children's cognitive and physical development, including linear growth, extends well beyond this period (Prentice et al. 2013), necessitating an understanding of how food insecurity impacts health beyond the fetal and infant periods. Weaned children, no longer nutritionally buffered by breastfeeding, may be at increased risk of health insults associated with food insecurity because of their increased dependence on household food for their nutritional needs. Further, research indicates that the lack of attention to low-income children's nutritional needs beyond the first years of life may undermine advances made during the early periods (Pérez-Escamilla \& Pollitt 1995), and reduce later cognitive development (Crookston et al. 2013).

In developing countries, the few studies of food security that include older children have found significant associations with increased risk of underweight in children ages 5-12 years (Isanaka et al. 2007), lower height-for-age z-scores at ages 5 and 8 years (Humphries et al. 2015), and underweight and stunting in children ages 2-12 years (Naser et al. 2014) and 7-14years (Wolde et al. 2015). However, these studies did not assess whether associations between food insecurity and child health differed by child age.

We would expect food insecurity to be more strongly associated with health in the early childhood years because of the rapid pace of growth (Lejarraga 2002) and less developed immune systems which, when compromised by poor nutrition and other factors, can reduce nutrient absorption (Dewey \& Mayers 2011). During these early years, children's nutritional requirements are complex, and a failure to meet their needs may be more consequential to their health (Herman et al. 2014). For example, evidence from developing countries suggests that low dietary diversity and insufficient iron intakes in early childhood can have important health effects, particularly the risk of anaemia (Netto et al. 2006) and low height-for-age (Marriott et al. 2012; Zongrone et al. 2012). These dietary issues may be more problematic in low-income settings where caregivers are constrained by limited education (Contreras et al. 2015; Ickes et al. 2015), cultural norms regarding child feeding (Nankumbi \& Muliira 2015) and economic pressures (Lindsay et al. 2012).

While early childhood is a critical period, older children may also be impacted by food insecurity. Older children require more kilocalories and protein in their diets than younger children (FAO/WHO/UNU 2001), and mothers may focus on younger children's nutritional needs more than on those of older children (Piperata et al. 2013). One study in urban Malaysia found that low-income older children (7-10years) had the worst dietary intakes, followed by children 4-6years of age. The youngest children (1-3 years) had more of their nutritional needs met (Shariff et al. 2015). Thus, older children may be equally or more vulnerable to household food insecurity than are younger children.

In addition to assessing potential differences in associations between household food insecurity and health by child age, we consider whether mild household food insecurity is associated with poor child health outcomes. Little research has been done in this area, because household food insecurity is often defined as a dichotomous variable that puts mildly food insecure households in the same category as food secure households. A recent US study found mild food insecurity to be associated with poorer health in children under 4 years old (Cook et al. 2013); however in other settings (Mexico and Colombia) no associations were found (Hackett et al. 2009; Cuevas-Nasu et al. 2014). We contribute to research and policy by empirically testing the

\section{Key messages}

- Mild and moderate to severe household food insecurity are associated with higher risks of illness, anaemia and low height-for-age in children in a developing country setting.

- Household food insecurity has strong associations with health outcomes in children ages $3-7$ years, but is less consequential for children ages 8 - II years.

- Public health policies could improve multiple child health outcomes by eliminating food insecurity in households with children. 
potential for even low levels of food insecurity to impact child health.

\section{Methods}

\section{Study setting and data}

Our study was conducted in Nicaragua, where $45 \%$ of the population lives on less than $\$ 1 /$ day (USAID 2005 ) and an estimated $27 \%$ of children live in households where family income is insufficient to ensure an adequate diet (UNICEF 2012). The data utilized here come from the Study of Food Insecurity and Maternal/Child Health implemented in the municipality of León, Nicaragua in 2012. The Department of León is Nicaragua's second largest municipality, with approximately $70 \%$ of the population living in urban areas (INIDE 2005). The study was designed and implemented by researchers from The Ohio State University and the Center for Demographic and Health Research at the Autonomous University of León (UNAN-León) to understand the links among socioeconomic conditions, food insecurity, diet and health in mothers and their children.

We randomly selected our sample households from an existing household survey representative of León. This allowed us to select households with at least one child ages 3-11 years from urban and rural areas of León. Rural areas were oversampled to ensure sufficient number of rural households. Trained social workers interviewed mothers about the household conditions, their own health and social status, and the health and schooling of one of their children ages 311 years (randomly selected if more than one child was in the age range). Biomarkers were collected by trained nurses from the mother and target child in their home during the interview. All procedures involving human subjects were approved by the Institutional Review Boards at The Ohio State University and UNAN-León. Verbal informed consent was witnessed and formally recorded for all participants, who were also reminded throughout the interview of their right to refuse to respond to any question or to terminate the interview. More details about the study design and data collection process for this project are provided in a recent publication (left out for blinded review).
The analytical sample utilized here includes households with valid maternal and child data, 431 of the original 500 selected households. Thirty households refused to participate, 27 were excluded from the sample because the mother was permanently absent, and two cases were excluded from the analysis because of missing data on the dependent variables.

\section{Measures}

Three child health outcomes are considered: illness (mother-reported), anaemia and low height-for-age. Child illness was coded as a dummy variable if the mother reported the child had a cough, fever, vomiting or diarrhoea in past two weeks. Maternal reports of child morbidity are common survey-based measures that have been validated across settings (Rousham et al. 1998). Anaemia was assessed using a HemoCue device. A small $(10 \mu \mathrm{L})$ sample of blood was collected by finger-prick and analysed on-site. The cut-offs for anaemia were as follows: children 36-59 months ( $\leq 109 \mathrm{~g} / \mathrm{dL})$; children 5-11 years $(\leq 114 \mathrm{~g} / \mathrm{dL})$ (WHO 2008). Our third dependent variable is low height-forage. Child height was measured in duplicate to the nearest mm using a portable Seca 210 stadiometer. Low height-for age is defined as one or more standard deviations below the mean of the age- and sex-specific reference population and, although not as severe as stunting, is a measure of chronic undernutrition (Frisancho 2008). Low height-for-age has also been defined as mild stunting and is an important health problem among children in the developing world (Stevens et al. 2012).

Household food insecurity was assessed using the Latin American and Caribbean Food Security Questionnaire (ELCSA), which was developed based on the US instrument (Nord 2009). ELCSA has been validated across the Latin American region as a reliable indicator of household-level food security (Gonzalez et al. 2008; Melgar-Quinonez \& Hackett 2008 Guerra et al. 2013). As part of our study design, we field-tested the ELCSA instrument through focus groups and interviews to adapt the wording for use in Nicaragua.

ELCSA consists of 15 questions related to household concerns and experiences with food scarcity over the past 3 months because of lack of sufficient money or 
resources. The aim of the questionnaire is to assess the respondents', in this case the mothers', perception of household experiences with food insecurity in four domains: (1) anxiety about household food supply; (2) perceptions that the quality or quantity of accessible food is inadequate; (3) reductions in intake among adult household members; and (4) reductions in intake among children in the home (Kennedy 2002). ELCSA and similar respondent-reported, experiential measures of household food security have been shown to be associated with household food expenditures, adult food intake and dietary diversity across settings (Jones et al. 2013). Following existing research (González et al. 2008), we classified household food ecurity status as follows: food secure (0 affirmative responses); mild food insecurity (1-5 affirmative responses); moderate or severe food insecurity (6-15 affirmative responses).

\section{Statistical Analysis}

We estimated three main models (child illness, child anaemia, child low height-for-age) with multivariate logistic regression using food secure households as the reference category. Standard errors were corrected for clustering and heteroskedasticity. Statistical significance of all variables was assessed through two-tailed $z$-tests of $p<0.05$. In presenting the descriptive results we show weighted means and percentages that account for oversampling of rural households. In the regression models, controlling for urbanicity accounted for the oversampling (Pfeffermann 1993). Odds ratios (exponentiated coefficients) and 95\% confidence intervals are presented for these main effects models. Secondary models were estimated including age interaction terms for both mild and moderate/severe food insecurity. Results from these models are presented as figures to illustrate significant differences $(p<0.05)$ in odds ratios by age for each outcome.

In estimating all models we included extensive control variables. At the child level we controlled for child parasite treatment within the past week, child age in years and child gender. Maternal characteristics included: social support (continuous 0-15 measure), income contribution (dummy variable if mothers contribute most to household income), management of household money (dummy variable if mother is the main manager of household money) and depressive symptoms (continuous 0-20 measure). More typical SES and household demographic controls were also included: maternal age, mother's pregnancy status (pregnant, not pregnant), low maternal education (primary school or less), mother currently working (yes, no), mother's marital status (married, cohabiting vs. single), age (in years) of the youngest child in the household, household size (continuous) and a household wealth index calculated using principal component analysis that integrated measures of household assets, housing quality, water availability and type of sanitation (Filmer \& Pritchett 2001). Additionally, migration remittances (defined as economic help given to the household in the past 6 months by family members or friends living outside of León or Nicaragua and measured as a yes/no dummy variable) and regular receipt of government cash assistance (such as from the national conditional cash transfer programme, Red de Protección Social) were included as other potential economic confounders, and, we controlled for whether the household was in a rural or urban area. In the low height-for-age models we added an additional control variable: maternal height.

\section{Results}

Table 1 shows the characteristics of the sample, weighted to account for the over sampling of rural households. Means are presented for the full sample and for the sample stratified by mean child age (7 years), which also corresponds to the age at which children move into the middle childhood or juvenile period. As Table 1 shows, child gender, recent parasite treatment and household characteristics are similar for younger (3-6years) and older (7-11 years) children. Mothers of older children were slightly more educated, more likely to be the main income earners and more often the main household money managers (Table 1).

Table 2 shows the distribution of households across the food insecurity categories. Twenty-five percent of households were food secure, $50 \%$ mildly food insecure 
Table I. Weighted characteristics of sample children, León, Nicaragua

\begin{tabular}{|c|c|c|c|}
\hline & \multicolumn{3}{|c|}{ Mean or \% (standard deviation) } \\
\hline & All & Age 3-6.9 & Age $7-10.9$ \\
\hline & $N=431$ & $n=235$ & $n=196$ \\
\hline \multicolumn{4}{|l|}{ Child characteristics } \\
\hline Child parasite treatment in past few weeks & $8 \%$ & $8 \%$ & $8 \%$ \\
\hline Child age in years & $6.7(1.9)$ & $5.2(1.0)$ & $8.5(0.9)$ \\
\hline Child male & $49 \%$ & $48 \%$ & $50 \%$ \\
\hline \multicolumn{4}{|l|}{ Maternal characteristics } \\
\hline Maternal social support & $10.3(2.9)$ & $10.3(2.8)$ & $10.2(3.0)$ \\
\hline Mother brings in most income & $20 \%$ & $18 \%$ & $23 \%$ \\
\hline Mother manages household money & $73 \%$ & $66 \%$ & $81 \%$ \\
\hline Maternal depressive symptoms & $5.4(4.3)$ & $5.3(4.1)$ & $5.6(4.5)$ \\
\hline Maternal age & $31(6.4)$ & $30(6.3)$ & $33(6.0)$ \\
\hline Mother pregnant & $4 \%$ & $4 \%$ & $3 \%$ \\
\hline Mother education primary school or less & $34 \%$ & $30 \%$ & $38 \%$ \\
\hline Mother working & $55 \%$ & $53 \%$ & $57 \%$ \\
\hline Mother married & $42 \%$ & $40 \%$ & $45 \%$ \\
\hline Mother cohabiting & $37 \%$ & $40 \%$ & $33 \%$ \\
\hline Mother single, divorced, separated or widowed & $21 \%$ & $20 \%$ & $22 \%$ \\
\hline \multicolumn{4}{|l|}{ Household characteristics } \\
\hline Age of youngest child in household (years) & $4.0(2.7)$ & $3.0(1.9)$ & $5.2(3.0)$ \\
\hline Household size & $8.6(4.1)$ & $8.8(4.3)$ & $8.3(3.8)$ \\
\hline Number of household assets & $9.3(3.2)$ & $9.3(3.0)$ & $9.4(3.4)$ \\
\hline Household received remittances in past 6 months & $14 \%$ & $13 \%$ & $14 \%$ \\
\hline Household receives government assistance & $4 \%$ & $4 \%$ & $3 \%$ \\
\hline
\end{tabular}

Table 2. Child health and food insecurity in households with children ages 3-I I years, León, Nicaragua. $N=43$ |

\begin{tabular}{|c|c|c|c|}
\hline & \multicolumn{3}{|c|}{ Mean/\% } \\
\hline & All & Age 3-6.9 & Age $7-10.9$ \\
\hline & $N=431$ & $n=235$ & $n=196$ \\
\hline \multicolumn{4}{|l|}{ Household food security } \\
\hline Food secure & $25 \%$ & $26 \%$ & $23 \%$ \\
\hline Mildly food insecure & $50 \%$ & $51 \%$ & $49 \%$ \\
\hline Mod./severely food insecure & $25 \%$ & $23 \%$ & $29 \%$ \\
\hline \multicolumn{4}{|l|}{ Child health indicators } \\
\hline Sick in past 2 weeks & $52 \%$ & $53 \%$ & $51 \%$ \\
\hline Had fever & $18 \%$ & $18 \%$ & $18 \%$ \\
\hline Had cough & $40 \%$ & $40 \%$ & $42 \%$ \\
\hline Had vomiting & $11 \%$ & $11 \%$ & $10 \%$ \\
\hline Had diarrhoea & $12 \%$ & $11 \%$ & $12 \%$ \\
\hline Anaemic & $23 \%$ & $27 \%$ & $20 \%$ \\
\hline Low height-for-age $(\mathrm{z}$-score $<-1)$ & $30 \%$ & $27 \%$ & $34 \%$ \\
\hline
\end{tabular}


and $25 \%$ either moderately or severely food insecure. Children under 7 years were slightly more likely to live in food secure households, while those 7-11 years old were more likely to live in households experiencing moderate or severe food insecurity (Table 2).

Table 2 also presents data on child health. Based on mothers' reports, $52 \%$ of the children were sick in the past two weeks. The most common illness was having a cough (40\%). Fever, vomiting and diarrhoea were reported in $18 \%, 11 \%$ and $12 \%$ of the children, respectively. The percent of children with any illness and by type of illness were similar among younger (ages 36 years) and older (7-11 years) age groups (Table 2). In addition to reported illnesses, 23\% of the children were anaemic and 30\% had low height-for-age. Anaemia was more prevalent in younger children $(p<0.05)$. Older children had a greater tendency for low height-for-age; however, means were not statistically significantly different $(p<0.06)$. The three health outcomes were not highly correlated $(r=.04-.08)$, and we found no statistically significant associations among these three measures in bivariate models. This suggests these are three independent aspects of children's health status that may be affected by household food insecurity.

Table 3 reports the results of multiple logistic regression models for child illness (model 1), child anaemia (model 2) and child low height-for-age (model 3). Both mild and moderate/severe food insecurity increased the odds of poor health across these measures, and operated in a dose-like response, with moderate to severe food insecurity having larger effects than mild food insecurity. Children in mildly food insecure households had $65 \%$ higher odds of experiencing an illness in

Table 3. Main effects of household food insecurity on child health outcomes. León, Nicaragua. $N=43$ ।

\begin{tabular}{|c|c|c|c|c|c|c|}
\hline \multirow[b]{2}{*}{ Variables } & \multicolumn{2}{|c|}{ Recent illness } & \multicolumn{2}{|c|}{ Anaemia } & \multicolumn{2}{|c|}{ Low height-for-age } \\
\hline & OR & $95 \%$ CI & OR & $95 \% \mathrm{CI}$ & OR & $95 \% \mathrm{CI}$ \\
\hline \multicolumn{7}{|l|}{ Household food security } \\
\hline Food secure & REF & & REF & & REF & \\
\hline Mildly food insecure & $1.65^{*}$ & $(1.03-2.64)$ & $1.59 * *$ & $(1.16-2.20)$ & $1.34 *$ & $(1.07-1.69)$ \\
\hline Moderately/severely food insecure & $3.14 *$ & $(1.27-7.78)$ & $2.23^{* *}$ & $(1.73-2.88)$ & $2.15^{* * *}$ & $(1.51-3.06)$ \\
\hline \multicolumn{7}{|l|}{ Controls } \\
\hline Recent parasite treatment & $2.84^{*}$ & $(1.20-6.69)$ & 1.29 & $(0.35-4.78)$ & 1.51 & $(0.52-4.34)$ \\
\hline Child age in years & 1.02 & $(0.91-1.15)$ & $0.85^{* *}$ & $(0.81-0.90)$ & $1.15^{* *}$ & $(1.10-1.20)$ \\
\hline Child male & 0.88 & $(0.43-1.78)$ & 0.94 & $(0.78-1.13)$ & 0.74 & $(0.38-1.43)$ \\
\hline Maternal height & & & & & $0.89 * *$ & $(0.84-0.93)$ \\
\hline Maternal social support & 0.98 & $(0.90-1.08)$ & 1.01 & $(0.96-1.06)$ & $0.85^{* * *}$ & $(0.84-0.87)$ \\
\hline Mother most income $^{a}$ & 1.10 & $(0.56-2.17)$ & 1.34 & $(0.84-2.15)$ & 0.76 & $(0.48-1.21)$ \\
\hline Mother manages money ${ }^{\mathrm{b}}$ & 0.66 & $(0.39-1.12)$ & 1.34 & $(0.39-4.64)$ & 1.36 & $(0.78-2.35)$ \\
\hline Maternal dep. symptoms & 1.10 & $(0.96-1.25)$ & 1.05 & $(0.98-1.13)$ & 0.97 & $(0.90-1.04)$ \\
\hline Maternal age & 0.98 & $(0.96-1.00)$ & 1.00 & $(0.97-1.03)$ & $0.96^{*}$ & $(0.92-0.99)$ \\
\hline Mother pregnant & 1.79 & $(0.74-4.35)$ & $2.34 * *$ & $(1.92-2.86)$ & 0.99 & $(0.54-1.83)$ \\
\hline Mother primary education $^{c}$ & $1.03 * *$ & $(1.01-1.05)$ & 1.18 & $(0.62-2.23)$ & 0.79 & $(0.48-1.29)$ \\
\hline Mother working & $2.17 * *$ & $(1.46-3.25)$ & 0.98 & $(0.72-1.35)$ & 0.77 & $(0.41-1.44)$ \\
\hline Mother married $^{\mathrm{d}}$ & 1.27 & $(0.55-2.94)$ & 1.28 & $(0.78-2.09)$ & 0.73 & $(0.22-2.44)$ \\
\hline Mother cohabiting & 1.35 & $(0.74-2.44)$ & 1.11 & $(0.55-2.25)$ & 0.60 & $(0.31-1.13)$ \\
\hline Age of youngest child & $0.89 * *$ & $(0.83-0.96)$ & 1.01 & $(0.99-1.03)$ & 1.08 & $(0.96-1.22)$ \\
\hline Household size & 0.98 & $(0.95-1.00)$ & 0.98 & $(0.91-1.06)$ & 1.03 & $(0.92-1.15)$ \\
\hline Household wealth & 0.92 & $(0.84-1.02)$ & 0.97 & $(0.74-1.26)$ & 0.91 & $(0.71-1.17)$ \\
\hline Received remittances & $2.24 * *$ & $(1.43-3.51)$ & 1.10 & $(0.88-1.38)$ & 0.44 & $(0.19-1.03)$ \\
\hline Government assistance & 1.20 & $(0.18-7.81)$ & 1.93 & $(0.99-3.78)$ & 1.26 & $(0.91-1.73)$ \\
\hline Urban area & 1.39 & $(0.59-3.24)$ & 0.59 & $(0.20-1.77)$ & 0.85 & $(0.23-3.10)$ \\
\hline
\end{tabular}

${ }^{\mathrm{a}}$ Ref: spouse, both or other person brings in most income. ${ }^{\mathrm{b}}$ Ref: spouse, mother and spouse, or other manages household money. ${ }^{\mathrm{c}}$ Ref: Above primary school education. ${ }^{\mathrm{d}}$ Ref: Mother single, divorced, separated or widowed. ${ }^{*} p<0.01 . * p<0.05$. 
the past 2 weeks, $60 \%$ higher odds of anaemia and $34 \%$ higher odds of low height-for-age compared with children living in food secure households. Children in moderate/severe food insecure households had over 3 times the odds of being ill and over 2 times the odds of being anaemic and having low-height-for-age compared with those children living in food secure households. These associations are net of extensive control variables. No other variables in the models were associated with all three measures of child health.

Among social and economic controls, low maternal education was associated with higher risk of illness, reflecting either lower quality care among less educated mothers or the socioeconomic status of the household not captured by the wealth measure. Working mothers were also more likely to report recent child illness. This may be because of lower quality care and inability to effectively prevent illness in situations where the mother worked outside the home. Higher maternal social support was associated with lower odds of low height-for-age, indicating the role of social and economic support for protecting children's health (Table 3).

Regression models with child age interactions were estimated by adding two variables: mild food insecurity $\times$ child age and moderate/severe food insecurity $\times$ child age. Figures 1-3 show the odds ratios estimated by the multivariate regression models. The results are remarkably consistent across the three outcomes: the effects of household food insecurity on child health decreased with child age; and, food insecurity was not significantly associated with any of the child health outcomes past age 7 years. Significance testing indicated that associations between food insecurity and our outcomes were not significantly different from zero beyond age 8 years; thus, the figures present the age interaction findings up to child age 8 years.

Figure 1 shows the results for child illness. The associations between mild food insecurity and illness did not differ significantly by child age. The moderate/severe food insecurity effect, however, did differ significantly by age. The highest odds of illness were at age 3 (the youngest children in the sample) with an estimated six-fold increase in the odds of being ill when living in a household experiencing moderate/severe food insecurity. This association declined with age and became statistically insignificant (not different from the odds of illness in food secure households) after age 7 years (Fig. 1).

Figure 2 shows the results for anaemia. The effects of mild household food insecurity differed significantly by child age for anaemia, with the strongest associations earlier in childhood. After age 6 years, mild household food insecurity was not significantly associated with children's odds of being anaemic (Fig. 2). Although the age interaction term for moderate/severe food insecurity was not statistically significant in the anaemia models, the age interaction and main effect of moderate/severe food insecurity were jointly significant. Further, the association between moderate/severe food insecurity and anaemia showed a similar pattern to the other outcomes, with stronger associations earlier and no significant association after age 7 years.

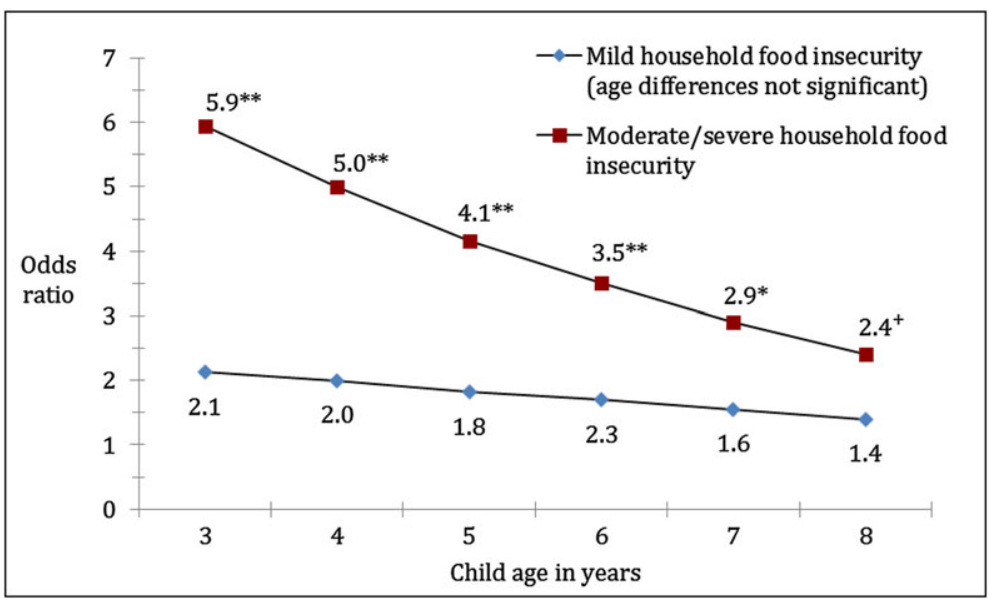

Fig. I Age interaction effects from illness logistic regression models. $N=431$. Significance tests of no difference from food secure household: *** $<0.01$; * $p<0.05$; ${ }^{+} \mathrm{p}<0$. I. All control variables indicated in Table 3 included in regression models. 

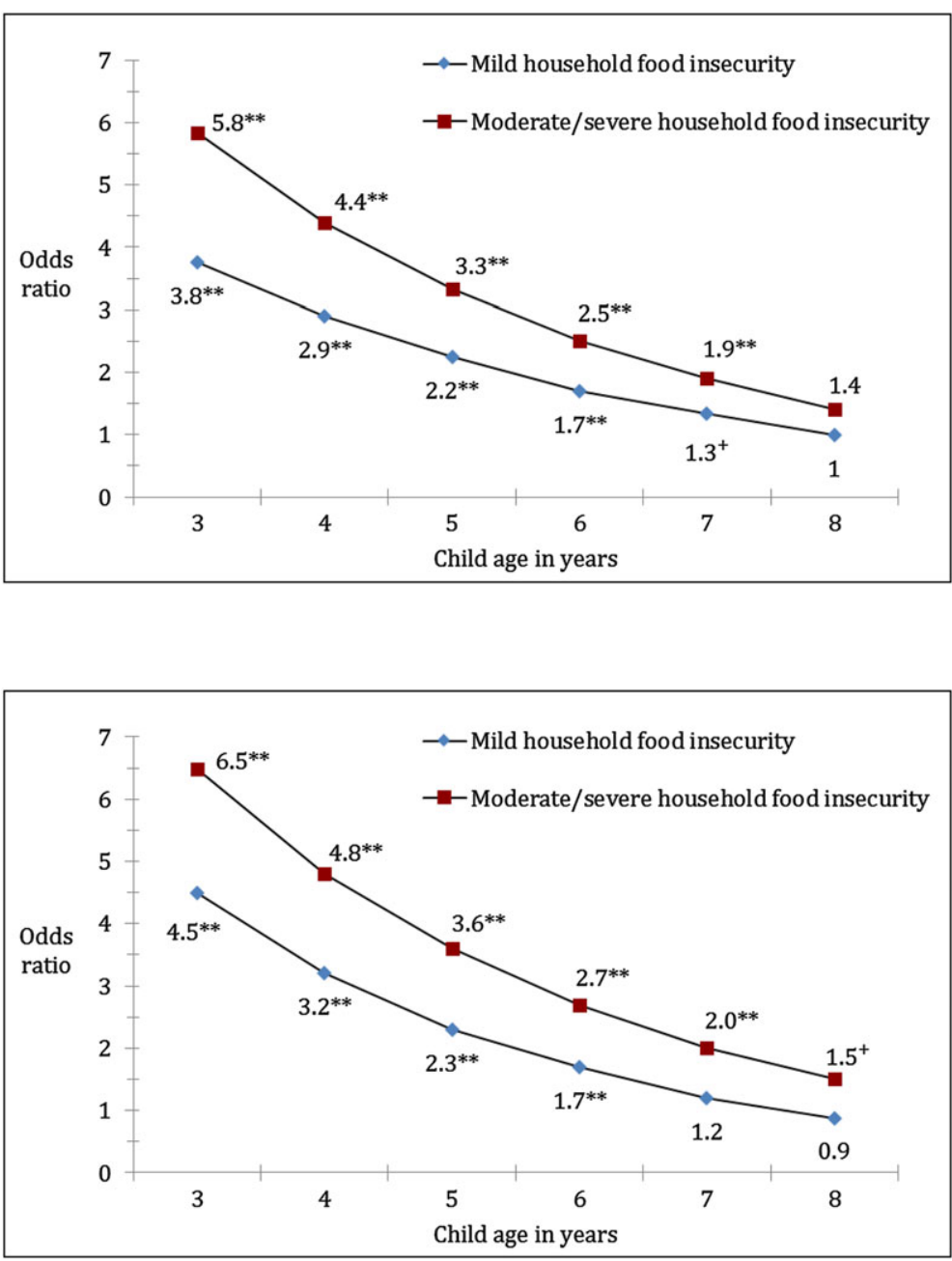

Fig. 2 Age interaction effects from anaemia logistic regression model. $N=431$. Significance tests of no difference from food secure household: *** $<0.01$; * $p<0.05 ;{ }^{+} p<0.1$. All control variables indicated in Table 3 included in regression models.
Fig. 3 Age interaction effects from low heightfor-age logistic regression model. $N=431$. Significance tests of no difference from food secure household: *** $p<0.0$ I; * $p<0.05$; ${ }^{+} \mathrm{p}<0.1$. All control variables indicated in Table 3 included in regression models.
Low-height-for-age regression results showed significant differences in the associations between mild and moderate/severe food insecurity and odds of lowheight-for-age by child age. Similar to the illness and anaemia findings, younger children were at highest risks of having low height-for-age when living in food insecure households (Fig. 3). After age 6 years, mild food insecurity was no longer significant, and after age 7 years, moderate/severe food insecurity was not significantly associated with low height-for-age.

\section{Discussion}

This study furthers our understanding of household food insecurity and child health in low-income settings by considering associations between mild and more severe levels of household food insecurity with multiple health measures for a sample of Nicaraguan children ages 3-11 years. Consistent with previous studies in developing nations (Hackett et al. 2009; Anderson et al. 2012, Cuevas-Nasu et al. 2014), our results indicated significant associations between household food insecurity and risk of illness, anaemia and low-height-for age among children. Both mild and moderate/severe household food insecurity were significantly associated with our health outcomes. Further, the average associations (across children 3-11 years) were quite large: moderate/severe household insecurity tripled the odds of illness and more than doubled the odds of anaemia and low height-for-age compared with the outcomes when children lived in food secure households. Odds 
ratios were even higher among the youngest children (ages 3-6 years). These are important, policy-relevant findings, given that $75 \%$ of the children in the sample lived in food insecure households, our use of extensive control variables and the strong associations across all three health outcomes.

Our finding of significant associations between mild food insecurity and our selected health outcomes is consistent with research in the USA that suggests that even marginal food insecurity is associated with poor child health (Cook et al. 2013). Although prior research in Mexico and Colombia did not find significant effects of mild food insecurity on stunting and underweight in young children (Hackett et al. 2009; Cuevas-Nasu et al. 2014), our findings indicate that mild food insecurity should be considered an important child health risk factor in our research setting.

We also theorized and empirically tested the moderating role of child age across the various levels of food insecurity and health outcomes. Our hypothesis that child age would moderate the effects of household food insecurity on child health was supported by significant interaction effects in multivariate regression models. Further analysis of the interaction effects showed consistency across the three outcomes in the age at which the associations between household food insecurity and child health became insignificant (age 7-8 years).

Both biological and socio-cultural factors may explain the stronger effects of food insecurity on child health at younger ages. Biologically, the combination of greater growth velocity and less-developed immune systems may increase the consequences of lack of adequate food for young children. Socio-culturally, younger children's greater dependence on and time spent in the household may further increase their vulnerability (physically and psychologically) to the effects of household food insecurity experiences. Further, young children beyond the breastfeeding years are dependent on their caregivers for nutritionally adequate food (Dewey \& Brown 2003). In León, nutrient-dense foods such as fresh meat, fruits and vegetables are more costly and thus consumed less frequently than corn tortillas, beans and rice, the dietary staples. Highly sugared beverages including powdered drink mixes and soda are also commonly consumed. This relatively low diversity diet may be insufficient to meet young children's needs. Furthermore, in this context, it was common for older children to serve as primary caregivers for their younger siblings, especially when their mothers' worked outside the home (Dahlblom et al. 2009). With limited dietary knowledge and power within the household, it is unlikely that older children can ensure that their younger siblings consumed an adequate diet.

Compared with younger children, older children may be more able to secure food outside the home and even contribute food to the household (Kramer 2005). For example, in this setting, most children over 6 years were attending school where they received food as part of a mid-morning snack or merienda, food younger children do not have access to. In addition, older children have slower growth rates and larger gut volumes compared with younger children. This means that, per unit body mass, their nutritional requirements are lower and their larger guts allow them to meet their dietary needs on less nutrient-dense foods. Thus, household food insecurity may be of less consequence to older children's physical health.

Importantly, although we found stronger effects at younger ages, food insecurity remained a significant predictor of child health up to age 8 years. Further, we did not find significant age differences in the association between mild food insecurity and illness, indicating similar risk of illness among younger and older children in food insecure households $(65 \%$ higher than for children in food secure households). By limiting samples to below age 5 years, including potentially protected breastfeeding infants, and focusing on only anthropometric outcomes past studies may have underestimated the effects of household food insecurity on child health.

Several limitations need to be taken into account. First, these data are cross sectional and are based on a representative sample of households with children in León, Nicaragua. Without longitudinal data it is more difficult to rule out spurious associations because of unobserved family or child factors. The findings can only be assumed to be associational and applicable to households with children in León.

Second, these findings are based on maternal reports of household food constraints experienced during the past 3 months. Although the ELCSA and similar experiential household food insecurity instruments 
have been validated across settings, the measures do not directly indicate dietary adequacy or consumption patterns in children (Jones et al. 2013). As part of this study, we collected detailed data on children's dietary intakes on a sub-sample of participating households. We plan to analyse these data in future publications in order to address differences in consumption patterns by child age and provide additional insights into the health outcomes reported here.

Finally, based on the allometric nature of growth, our chosen health measures may be biased toward younger children, particularly low height-for-age. However, in this sample, younger and older children had similar sample means for illness and low stature - only anaemia was significantly higher ( $27 \%$ vs. $20 \%$ ) in younger children. Further, our use of recent illness and anaemia as outcomes provided the opportunity to assess food insecurity effects on outcomes that are less cumulative than height. Although the consistent lack of significant associations between food insecurity and our health measures among children over age 8 years may reflect that household food security is less important for health at these ages, it may also be that the health of older children was affected by household food security at an earlier age, which we would not capture with crosssectional data and the ELCSA measure. Longitudinal evidence from a prior study, however, pointed to the importance of food insecurity at age 8 , more than food insecurity at age 5 , for lower height-for-age at age 8 . This suggests that recent food insecurity may have a stronger association with child health than past food insecurity (Humphries et al. 2015). The study did not assess associations at later child ages (after age 8 years), when we found no significant associations. Subsequent studies should further test the timing of food insecurity effects using longitudinal data for a broad age range of children.

Despite these limitations, this study makes an important contribution to our understanding of the associations between food insecurity and child health in the developing world. Our study points to household food insecurity as important for child health net of socioeconomic and demographic conditions (including maternal education). While reducing household poverty may require long-term strategies, improving access to nutrientdense food in low SES contexts may provide benefits to child health in the short term. Further, even smaller improvements in the household food environment, such as moving households from mildly insecure to food secure, could benefit child health.

Finally, our results indicate significant associations across health outcomes among children over age 4 years, a group that is often not targeted by child health and nutrition policy. While we recognize the importance of the first 1000 days, our study suggests that policies and interventions need to go beyond this period. Although infants are biologically more vulnerable to malnutrition, as children age, social, economic and cultural conditions (in addition to biology) shape their health outcomes in different ways and require continued attention to nutritional issues. This is not a new idea; a study in the 1990s showed that nutritional interventions improved outcomes among malnourished pre-school children; and, that stopping the intervention prevented further nutritional advances (Pérez-Escamilla \& Pollitt 1995). More recently, attention has been given to growth periods after 1000 days (Leroy et al. 2014). Our research furthers research in this area, indicating that children in low-income settings are vulnerable to the health effects of food insecurity beyond the first years of life, across multiple health outcomes and at low levels of food insecurity. This suggests that attention to one stage of growth and development or only the most severe hunger conditions will not provide the child health and nutrition improvements that the Millennium Development Goals and other policies hope to attain.

\section{Acknowledgements}

We thank the following project collaborators from the Center for Demographic and Health Research (CIDS) at UNAN-León: Andrés Herrera Rodríguez, Virgilio Mariano Salazar Torres, Francisco José Centeno Cárdenas, Margarita Chévez Díaz, Armando Benito Camacho, Perla Zeledón Zeledón, Aleyda Fuentes Reyes, Carla Quiroz López, and Napoleón Vásquez Álvarez. This work could not have been completed without the extraordinary effort of our field team members: Yasuara Rivas Narváez, Walquiria Orozco, Reyna Duarte Calderón, Yuvielka Martínez Suazo, 
Ana Olivares Torres, María Morales Vargas, Karla Espinoza Montalván, Gabriela Quintanilla Hernández, and Silvia Medrano Áviles. We also thank our data entry personnel: Jasmin Fuentes Membreño, Luz Delgado Centeno, Blanca Chavarria García, and Rene Lucía Delgado.

\section{Financial Support}

Partial funding for this research was provided by The Ohio State University Office of Outreach and Engagement and Office of International Affairs

\section{Conflict of Interest}

The authors declare that they have no conflicts of interest.

\section{Contributions}

The study research questions and study design were jointly formulated by KKS and BAP. Data analysis was conducted by KKS. Writing of the article was conducted by KKS with substantial input from BAP.

\section{References}

Allen L.H. (2006) Causes of nutrition-related public health problems of preschool children: Available diet. Journal of Pediatric Gastroenterology and Nutrition 43, S8-S12.

Anderson L.C., Tegegn A., Tessema F., Galea S. \& Hadley C. (2012) Food insecurity, childhood illness and maternal emotional distress in Ethiopia. Public Health Nutrition 15, 648-655.

Campbell A.A., Akhter N., Sun K., De Pee S., Kraemer K., Moench-Pfanner R. et al. (2011) Relationship of household food insecurity to anaemia in children aged 6-59 months among families in rural Indonesia. Annals of Tropical Paediatrics 31, 321-330.

Coleman-Jensen A., Mcfall W. \& Nord M. (2013) Food insecurity in households with children: prevalence, severity, and household characteristics, 2010-11USDA. In: Economic Information Bulletin. Department of Agriculture: Washington, D.C.: US.
Contreras M., Blandon E. Z., Persson L. A., Hjern A. \& Ekstrom E. C. (2015) Socio-economic resources, young child feeding practices, consumption of highly processed snacks and sugar-sweetened beverages: a population-based survey in rural northwestern Nicaragua. Bmc Public Health 15.

Cook J.T., Black M., Chilton M., Cutts D., De Cuba S.E., Heeren T.C. et al. (2013) Are food insecurity's health impacts underestimated in the us population? Marginal food security also predicts adverse health outcomes in young $\mathrm{U}$. S. children and mothers. Advances in Nutrition 4, 51-61.

Crookston B.T., Schott W., Cueto S., Dearden K.A., Engle P., Georgiadis A. et al. (2013) Postinfancy growth, schooling, and cognitive achievement: young lives. American Journal of Clinical Nutrition 98, 1555-1563.

Cuevas-Nasu L., Rivera-Dommarco J.A., Shamah-Levy T., Mundo-Rosas V. \& Humaran I.M.G. (2014) Food insecurity and nutritional status of preschool children in Mexico. Salud Publica De Mexico 56, S47-S53.

Currie J. \& Vogl T. (2013) Early-life health and adult circumstance in developing countries. Annual Review of Economics 5, 1-36.

Dahlblom K., Herrara A.R., Peña R. \& Dahlgren L. (2009) Home alone: children as caretakers in León, Nicaragua. Children \& Society 23, 43-56.

Dewey K.G. \& Brown K.H. (2003) Update on technical issues concerning complementary feeding of young children in developing countries and implications for intervention programs. Food and Nutrition Bulletin-United Nations University 24, 5-28.

Dewey K.G. \& Mayers D.R. (2011) Early child growth: how do nutrition and infection interact? Maternal \& Child Nutrition 7 (Suppl 3), 129-42.

FAO (2014) The State of Food Insecurity in the World 2014. FAO: Rome.

FAO/WHO/UNU (2001) Human Energy Requirements. FAO: Rome.

Filmer D. \& Pritchett L.H. (2001) Estimating wealth effects without expenditure data-or tears: an application to educational enrollments in states of India. Demography $\mathbf{3 8}$, $115-132$.

Frisancho A.R. (2008) Anthropometric Standards. An Interactive Nutritional Reference of Body Size and Body Composition for Children and Adults, $2^{\text {nd }}$ edn. University of Michigan Press: Ann Arbor.

González W., Jiménez A., Madrigal G., Muñoz L.M. \& Frongillo E.A. (2008) Development and validation of measure of household food insecurity in urban Costa Rica confirms proposed generic questionnaire. The Journal of Nutrition $\mathbf{1 3 8}$ 587-592.

Guerra L.D.D., Espinosa M.M., Bezerra A.C.D., Guimaraes L.V. \& Lima-Lopes M.A. (2013) Food insecurity in households with adolescents in the Brazilian Amazon: prevalence and associated factors. Cadernos De Saude Publica 29, 336-349. 
Hackett M., Melgar-Quinonez H. \& Alvarez M.C. (2009) Household food insecurity associated with stunting and underweight among preschool children in Antioquia, Colombia. Revista Panamericana De Salud Publica-Pan American Journal of Public Health 25, 506-510.

Hadley C. \& Crooks D.L. (2012) Coping and the biosocial consequences of food insecurity in the 21st century. American Journal of Physical Anthropology 149, 72-94.

Hadley C., Tessema F. \& Muluneh A.T. (2012) Household food insecurity and caregiver distress: equal threats to child nutritional status? American Journal of Human Biology 24, 149-157.

Herman D.R., Baer M.T., Adams E., Cunningham-Sabo L., Duran N., Johnson D.B. et al. (2014) Life course perspective: evidence for the role of nutrition. Maternal and Child Health Journal 18, 450-461.

Humphries D.L., Dearden K.A., Crookston B.T., Fernald L.C., Stein A.D., Woldehanna T. et al. (2015) Cross-sectional and longitudinal associations between household food security and child anthropometry at ages 5 and 8 years in Ethiopia, India, Peru, and Vietnam. Journal of Nutrition 145, 1924-1933.

Ickes S.B., Hurst T.E. \& Flax V.L. (2015) Maternal literacy, facility birth, and education are positively associated with better infant and young child feeding practices and nutritional status among Ugandan children. Journal of Nutrition 145, 2578-2586.

INIDE (2005) VIII Censo de Población y IV de Vivienda, Municipio de León. INIDE: Managua.

Isanaka S., Mora-Plazas M., Lopez-Arana S., Baylin A. \& Villamor E. (2007) Food insecurity is highly prevalent and predicts underweight but not overweight in adults and school children from Bogota, Colombia. Journal of Nutrition 137, 2747-55.

Jones A.D., Ngure F.M., Pelto G. \& Young S.L. (2013) What are we assessing when we measure food security? A compendium and review of current metrics. Advances in Nutrition 4, 481-505.

Kennedy E. (2002) Qualitative measures of food insecurity and hunger. Keynote paper for the international scientific symposium on measurement and assessment of food deprivation and undernutrition. International Scientific Symposium on Measurement and Assessment of Food Deprivation and Undernutrition, 2002 Rome. FAO.

Kramer K.L. (2005) Children's help and the pace of reproduction: cooperative breeding in humans. Evolutionary Anthropology: Issues, News, and Reviews 14, 224-237.

Kursmark M. \& Weitzman M. (2009) Recent findings concerning childhood food insecurity. Current Opinion in Clinical Nutrition \& Metabolic Care 12, 310-316.

Lejarraga, H. (2002) Growth in infancy and childhood: a pediatric approach. In: Cameron N. \& Bogin B. (eds.) Human Growth and Development. Academic Press: San Diego.

Leroy J.L., Ruel M., Habicht J.P. \& Frongillo E.A. (2014) Linear growth deficit continues to accumulate beyond the first 1000 days in low- and middle-income countries: global evidence from 51 national surveys. Journal of Nutrition 144, 1460-1466.

Lindsay A.C., Ferarro M., Franchello A., De La Barrera R., Machado M.M.T., Pfeiffer M.E. et al. (2012) Child feeding practices and household food insecurity among lowincome mothers in Buenos Aires, Argentina. Ciência \& Saúde Coletiva 17, 661-669.

Marriott B.P., White A., Hadden L., Davies J.C. \& Wallingford J.C. (2012) World Health Organization (WHO) infant and young child feeding indicators: associations with growth measures in 14 low-income countries. Maternal and Child Nutrition 8, 354-370.

Melchior M., Chastang J.F., Falissard B., Galera C., Tremblay R.E., Cote S.M. et al. (2012) Food insecurity and children's mental health: a prospective birth cohort study. Plos One 7.

Melgar-Quinonez H. \& Hackett M. (2008) Measuring household food security: the global experience. Journal of Physical Therapy Science 21, 27-37.

Nankumbi J. \& Muliira J.K. (2015) Barriers to infant and childfeeding practices: a qualitative study of primary caregivers in rural Uganda. Journal of Health, Population, and Nutrition 33, 106-116.

Naser I.A., Jalil R., Muda W.M.W., Nik W.S.W., Shariff Z.M. \& Abdullah M.R. (2014) Association between household food insecurity and nutritional outcomes among children in northeastern of peninsular Malaysia. Nutrition Research and Practice 8, 304-311.

Netto M.P., Priore S.E., Sant'ana H.M.P., Peluzio M.D.G., Sabarense C.M., Da Silva D.G. et al. (2006) Prevalence and factors associated to anemia and iron deficiency in 18to 24-month old infants. Archivos Latinoamericanos de Nutrición 56, 229-236.

Nord M. (2009) Food insecurity in households with children: prevalence, severity, and household characteristics. In: Economic Information Bulletin (ed. USDA). Department of Agriculture: Washington, D.C.: U.S.

Nord M. (2014) What have we learned from two decades of research on household food security? Public Health Nutrition 17, 2-4.

Pérez-Escamilla R. \& Pollitt E. (1995) Growth improvements in children above 3 years of age-the Cali study. Journal of Nutrition 125, 885-893.

Pfeffermann D. (1993) The role of sampling weights when modeling survey data. International Statistical Review/Revue Internationale de Statistique 61, 317-337.

Piperata B.A., Schmeer K.K., Hadley C. \& Ritchie-Ewing G. (2013) Dietary inequalities of mother-child pairs in the rural Amazon: evidence of maternal-child buffering? Social Science \& Medicine 96, 183-191.

Prentice A.M., Ward K.A., Goldberg G.R., Jarjou L.M., Moore S.E., Fulford A.J. et al. (2013) Critical windows for nutritional interventions against stunting. American Journal of Clinical Nutrition 97, 911-918. 
Rousham E.K., Northrop-Clewes C.A. \& Lunn P.G. (1998) Maternal reports of child illness and the biochemical status of the child: the use of morbidity interviews in rural Bangladesh. British Journal of Nutrition 80, 451-456.

Shariff Z.M., Lin K.G., Sariman S., Lee H.S., Siew C.Y., Yusof B.N.M. et al. (2015) The relationship between household income and dietary intakes of 1-10 year old urban Malaysian. Nutrition Research and Practice 9, 278-287.

Stevens G.A., Finucane M.M., Paciorek C.J., Flaxman S.R., White R.A., Donner A.J. et al. (2012) Trends in mild, moderate, and severe stunting and underweight, and progress towards mdg 1 in 141 developing countries: a systematic analysis of population representative data. Lancet 380, 824-834.
UNICEF (2012) Child Poverty in Latin America. In: UNICEF (ed.). UNIFEC: New York.

USAID (2005) The governance dimensions of food insecurity in Nicaragua.

WHO (2008) Worldwide Prevalence of Anaemia 1993-2005: WHO Global Database on Anaemia. World Health Organization: Geneva.

Wolde M., Berhan Y. \& Chala A. (2015) Determinants of underweight, stunting and wasting among schoolchildren. BMC Public Health 15.

Zongrone A., Winskell K. \& Menon P. (2012) Infant and young child feeding practices and child undernutrition in Bangladesh: insights from nationally representative data. Public Health Nutrition 15, 1697-1704. 